\title{
Airtime Credit Banking: From Two Applications to One Application
}

\author{
Iorliam Aamo1, Atu Myom', Yahaya I. Shehu² \\ ${ }^{1}$ Department of Mathematics/Computer Science, Benue State University, Makurdi, Nigeria \\ ${ }^{2}$ Shehu Shagari College of Education, Sokoto, Nigeria \\ Email:miorliam@yahoo.com, atumyom@gmail.com,yishehu@yahoo.com
}

How to cite this paper: Aamo, I., Myom, A. and Shehu, Y.I. (2017) Airtime Credit Banking: From Two Applications to One Application. Journal of Computer and Communications, 5, 10-15. https://doi.org/10.4236/jcc.2017.510002

Received: July 7, 2017

Accepted: August 6, 2017

Published: August 9, 2017

Copyright (C) 2017 by authors and Scientific Research Publishing Inc. This work is licensed under the Creative Commons Attribution International License (CC BY 4.0).

http://creativecommons.org/licenses/by/4.0/

\section{c) (i) Open Access}

\begin{abstract}
This paper proposes how airtime credit could be used for banking purposes. The aim is to provide a means of converting airtime credit of any network service provider to a credit alert for a particular bank account user. This paper shows a simple implementation of the proposed system. The advantage of the proposed system is that it allows customers the right to convert their purchased airtime credit to a credit alert at anytime when they no longer wish to use the airtime credit again. Furthermore, it explains the limitations of the proposed system considering regulations in different countries of deployment. This approach could be extended to cover other vouchers for banking applications as well.
\end{abstract}

\section{Keywords}

Airtime Credit, Banking, Voucher

\section{Introduction}

Airtime credit is defined as a recharge card or top-up card bought by a mobile phone user to aid him/her recharge/top-up his/her phone. This could assist the user in making calls, sending short message service (SMS) and obtaining bundles for browsing purposes. When phones are loaded with airtime credit they have great advantages such as making relationships stronger, aiding very clear communication, and marketing purposes [1] amongst several other advantages.

Even though, airtime credit when loaded presents huge advantages, some people could change their mind after purchasing the airtime credit. Moreover, if an airtime credit is sent to someone as a gift, the person should have the option of converting it to cash in his bank account in order to use it for something else in the future. 
Banking on the other hand could be defined as "the business activity of accepting and safeguarding money owned by other individuals and entities, and then lending out this money in order to earn a profit". It is considered as a highly regulated industry and as such government has always varied the regulations relating to banking based on the need at a particular era and country [2].

We have observed that it has been a very easy process of purchasing recharge cards/top-ups on automated teller machines (ATMs). However, the reverse process of changing such recharge cards/top-ups to an equivalent amount in a person's bank account has not been implemented. Therefore, we propose a system to convert airtime credit to an equivalent amount into the airtime credit holder's bank account.

A company called Paysob [3] has implemented a software that is closely related to this proposed system. However, they only pay for goods and services using these recharge cards. Furthermore, they are limited to accepting only recharge cards from MTN network. Motivated by Paysob [3], this paper proposes a simple but important method for the conversion of airtime credit to bank account money. In the next section, related literature is considered and the need to implement the proposed system is highlighted.

\section{Related Work}

Banking systems have provided different ways to accept cash into a particular account of interest. Cash or cash equivalents could be defined as: "balance sheet items that represent either physical money on hand or in bank accounts and other assets that can be easily converted to cash without a significant loss in their value" [4].

This means money equivalent could be any valuable "thing" that could be used in place of any acceptable cash in a particular country or nation.

Some of the methods in which cash could exist are briefly described below:

1) Physical Cash: Physical cash in a person's pocket or wallet could be used to deposit money into a particular account of interest or pay for goods and services. This has been the most common way in which most third world countries deposit money into their accounts or pay for goods or services. The use of physical cash could be traced back to when coins were used in the island of Aegina around the 700BC [5].

2) Cheques: A cheque is an order to a bank to either pay a person or credit a particular account (usually accompanied by a written instruction in some cases) based on a particular instructed sum. This method has been used for cash withdrawal, payment for goods and services since the first century Before Common Era (BCE) in the ancient Romans [6].

3) Credit Cards: Credit cards are used for purchasing items/withdrawal of money even if a particular person does not have such an amount at the time of purchase. Sometimes, these cards could be used to transfer cash to other accounts 
as well. This method has been into existence since the 1920s in the United States [7].

4) Debit cards: These cards are very similar to credit cards. This card however, allows you to use only the money you owe in your bank account. This method came into existence since 1966 and the Bank of Delaware piloted it [8].

5) Pre-paid (pre-loaded) cards: This card works by transferring money from your bank to the pre-paid (pre-loaded) card before it could be used. It could also be used to withdraw/transfer cash sometimes with a charge [9].

Even though, there are several methods in which cash could be deposited into our banks. There is need to provide more ways in which cash could be deposited. To the best of our knowledge, converting airtime credit to bank money so it could be used as cash has not been proposed nor implemented. Hence, we are motivated to propose and implement this method.

\section{Methodology}

The proposed system comprises of two major components: 1) Administrator; 2) General airtime credit seller. The administrator creates the network type (e.g. MTN, AIRTEL, GLO, ETISALAT etc.) and Bank name (e.g. DIAMOND BANK, SKYE BANK, FIRST BANK, GTB etc.), manage users account, view generated credit pins, view reports of sold credit pins. Whereas, the general airtime credit sellers could create an account, view account balance, and sell credit cards (selects the network type, enters a card pin, selects the bank name and account number). The user proceeds by submitting the details so that his/her bank could be credited. Figure 1 shows the pictorial representation of the proposed system.

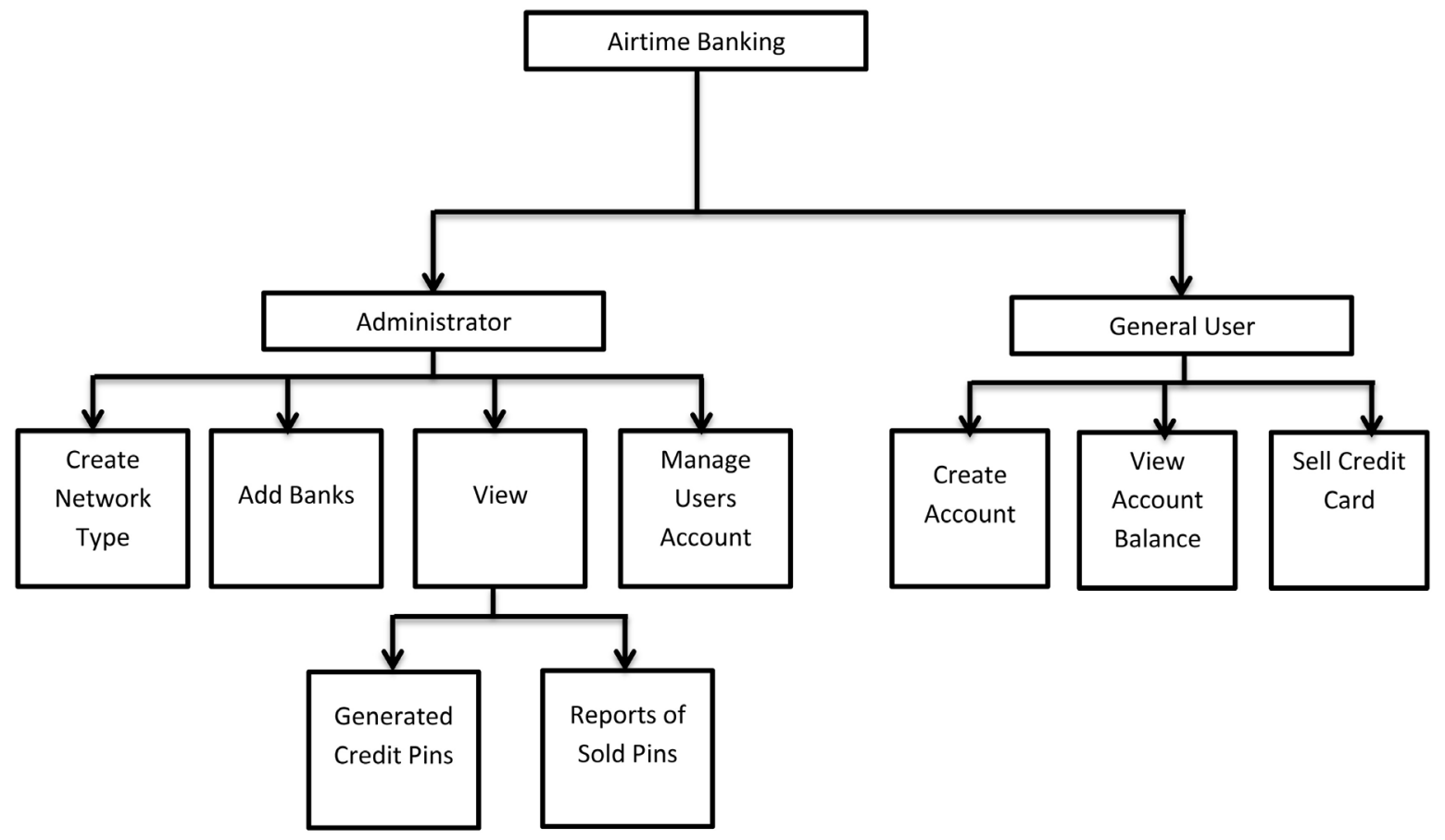

Figure 1. Pictorial representation of the proposed system. 
The system has an adjustable percentage parameter to be deducted from the airtime credit that is to be converted to bank money. This adjustable parameter could be easily set (e.g. $5 \%, 10 \%$ of the airtime credit) depending on the choice of the system administrator and what the regulatory body in the country of deployment accepts. In Nigeria where this system is proposed, we anticipate to comply with the Central Bank of Nigeria (CBN) and Nigerian Communications Commission (NCC) regulations if the system is deployed in real life.

The proposed system is very simple, and our goal is not to make it outperform any similar system. It is only to demonstrate the possibility of how airtime credit could be converted to bank money in a very efficient and simple way. Our proposed system was developed using Hypertext Preprocessor (PHP) [10] and could be tested at http://sms.wapteg.com.ng/airtimebanking/sellcredit.php. Note that the username and password could be requested from the authors of this paper for testing purposes and further upgrading purposes.

We chose PHP because it has proved to be very effective in well existing systems such as WordPress, Facebook, and it has proved to be a very effective server side language. Again, due to its compatibility advantage on different platforms such as Linux, Unix, Mac OS X, and Windows makes it a more suitable language for this proposed system. Considering compatibility with servers (e.g. Apache, IIS, etc.), it is considered as one of the most suitable [10].

Figure 2 shows an interface of how the proposed system could easily and smartly convert airtime credit to bank money.

When a user of the airtime banking selects the network of the airtime credit he/she intends to convert to bank money, he/she will enter the card pin, select the bank name and enter the bank account number, then he/she can easily sell

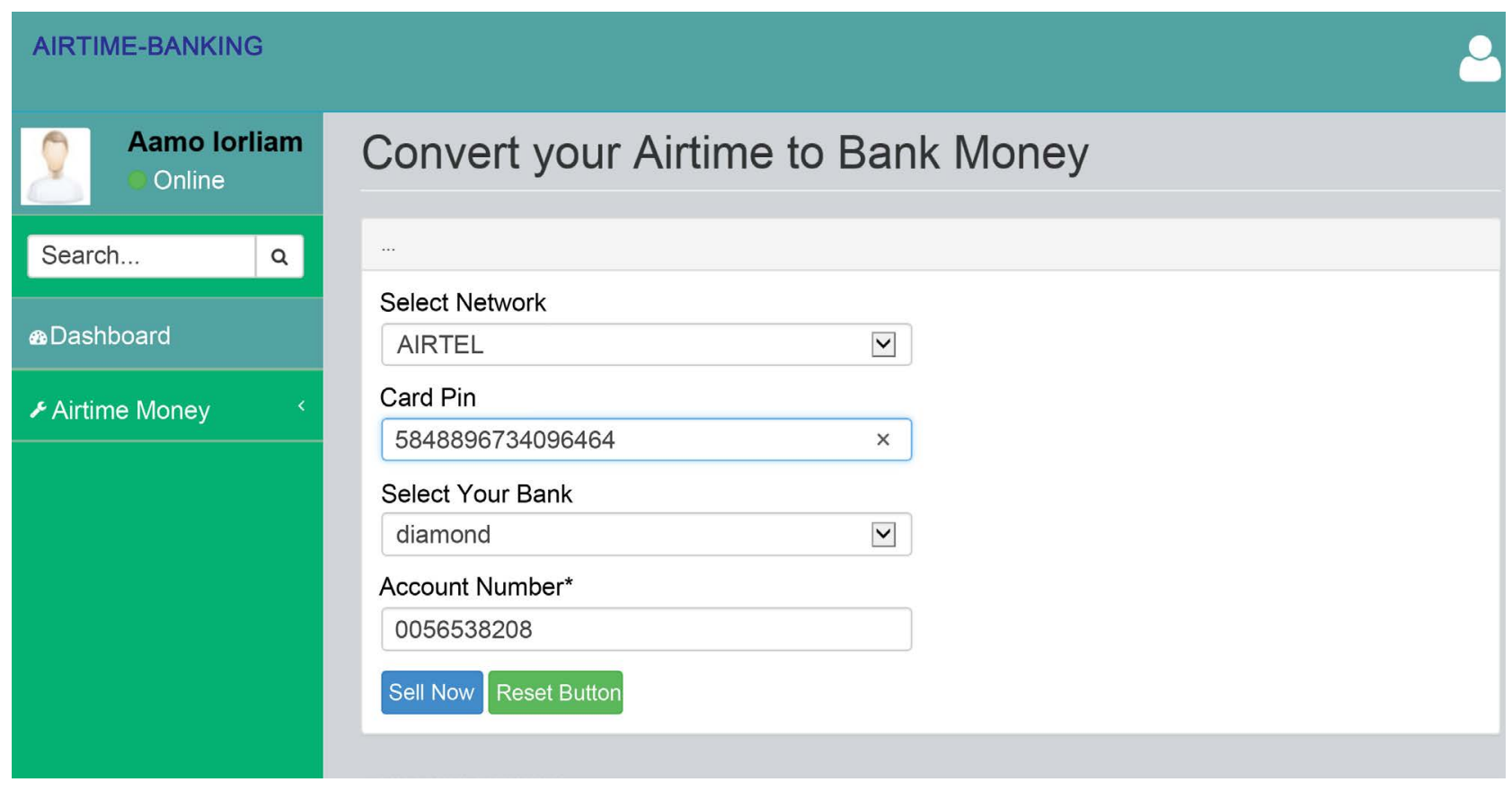

Figure 2. Interface of the proposed system. 
the airtime credit. The corresponding bank account gets credited after the airtime credit is sold.

\section{Limitations and Challenges of the Proposed System}

The proposed system is only a prototype and needs to be deployed in collaboration with banking application systems and telecommunication companies. However, implementing this system needs the approval of the right authorities. For example, in Nigeria, the CBN and NCC needs to study this system, investigate the negative side effects and will make a decision as to whether to accept/decline its implementation in real life. However, we are hopeful that if the proposed system is implemented in real life, it will be very useful in solving the huge challenge of converting airtime credit to bank money when there is a need for this purpose.

\section{Conclusions and Future Work}

This paper investigates the possible combination of airtime credit and banking application to become one application. In our literature search, and to the best of our knowledge, this system has not been implemented. Our proposed system has several advantages if deployed in real life. This proposed system is promising, especially due to its very simple structure and easy deployment. We encourage researchers and government regulatory bodies to contribute in making this system deployable in real life.

In our future work, we hope to extend this proposed system to convert vouchers to banking money.

\section{Acknowledgements}

Sincere thanks to my Benue State University, computer science students, Idikwu Joseph Sunday, Angela Ebute and Kwembe Lawrence for some useful discussions concerning the proposed system.

\section{References}

[1] Brewers, P. (2017) The Advantages of the Telephone. https://www.navitor.com/blog/advantages-telephone/

[2] Emonics (2017) Banking and Financial Institutions. http://www.emonics.com/banking-and-financial/

[3] Paysob (2012) Accept payments by recharge cards. https://paysob.com/

[4] Simple Studies (2010) How to Account for Bank Deposits? http://simplestudies.com/how-to-account-for-bank-deposit.html

[5] Snible (n.d.) Aegina. http://snible.org/coins/hn/aegina.html

[6] Will, D. (1944) Caesar and Christ: A History of Roman Civilization and of Christianity from Their Beginnings to AD 325. Blackstone AudioBooks, Ashland.

[7] The Editors of Encyclopædia Britannica (2017) Credit Card. https://www.britannica.com/topic/credit-card 
[8] Collins, J. (2011) A Short History of the Debit Card. https://www.marketplace.org/2011/08/18/business/news-brief/short-history-debit-card

[9] Connectability (2013) Different Ways to Buy Things like Goods and Services. http://connectability.ca/2013/01/18/different-ways-to-buy-things-like-goods-and-se rvices/

[10] The World's Largest Web Developer Site (1999-2017) PHP 5 Introduction. https://www.w3schools.com

Submit or recommend next manuscript to SCIRP and we will provide best service for you:

Accepting pre-submission inquiries through Email, Facebook, LinkedIn, Twitter, etc. A wide selection of journals (inclusive of 9 subjects, more than 200 journals)

Providing 24-hour high-quality service

User-friendly online submission system

Fair and swift peer-review system

Efficient typesetting and proofreading procedure

Display of the result of downloads and visits, as well as the number of cited articles Maximum dissemination of your research work

Submit your manuscript at: http://papersubmission.scirp.org/

Or contact jcc@scirp.org 